\title{
A Subjective Test of Modulated Blade Spacing for Helicopter Main Rotors
}

\author{
Brenda M. Sullivan \\ b.m.sullivan@larc.nasa.gov \\ Aerospace Engineer \\ NASA Langley Research Center, Hampton, Virginia \\ Bryan D. Edwards \\ BEdwards2@bellhelicopter.textron.com \\ Technical Resource Specialist, Acoustics \\ Bell Helicopter Textron, Fort Worth, Texas \\ Kenneth S. Brentner \\ ksbrentner@psu.edu \\ Associate Professor \\ The Pennsylvania State University, University Park, Pennsylvania \\ Earl R. Booth, Jr \\ e.r.booth@1arc.nasa.gov \\ Senior Research Engineer \\ NASA Langley Research Center, Hampton, Virginia
}

\begin{abstract}
Analytically, uneven (modulated) spacing of main rotor blades was found to reduce helicopter noise. A study was performed to see if these reductions transferred to improvements in subjective response. Using a predictive computer code, sounds produced by six main rotor configurations: 4 blades evenly spaced, 5 blades evenly spaced and four configurations with 5 blades with modulated spacing of varying amounts, were predicted. These predictions were converted to audible sounds corresponding to the level flyover, takeoff and approach flight conditions. Subjects who heard the simulations were asked to assess the overflight sounds in terms of noisiness on a scale of 0 to 10 . In general the evenly spaced configurations were found less noisy than the modulated spacings, possibly because the uneven spacings produced a perceptible pulsating sound due to the very low fundamental frequency.
\end{abstract}

\section{INTRODUCTION}

More rotorcraft operations are occurring in and near population centers, resulting in more public awareness of the noise associated with these operations. Because of this increased awareness, rotorcraft operations are being constrained by local governments and by regulatory bodies in the form of more stringent noise specifications. These specifications are a requirement for civil certification of rotorcraft. The increasing market sensitivity to rotorcraft noise has fueled the search for rotorcraft design innovations that will reduce noise without placing impractical penalties on cost or performance. This paper describes an investigation of one potential noise reduction design feature.

Presented at the American Helicopter Society 58th Annual Forum, Montréal, Canada, June 11-13, 2002. Copyright (C) 2002 by the American Helicopter Society International, Inc. All rights reserved.

\section{Modulated Blade Spacing Concept}

The National Aeronautics and Space Administration (NASA) has an ongoing program to develop technology which will reduce aircraft, including rotorcraft, noise. NASA's overall Aerospace Technology Enterprise goals are to reduce perceived noise levels of future aircraft by a factor of 2 from today's subsonic aircraft within 10 years and by a factor of 4 within 20 years. The current study supports these goals specifically for future helicopters and, by similarity, for future tiltrotor aircraft.

In September 1998, NASA requested proposals for innovative, high-risk design features to reduce helicopter main rotor noise. Bell responded with a proposal to evaluate the noise reduction potential of Modulated (uneven) Blade Spacing (MBS) as applied to helicopter main rotors. The primary characteristic of this nontraditional 5-blade rotor concept is that the blade spacings, rather than being a constant $72^{\circ}$ as in a traditional 5-blade rotor, have five unique spacings. Bell's Model 427 
helicopter was chosen as a baseline for comparison. A 5blade evenly spaced rotor with a comparable payload-range was designed, from which were derived the 5-blade MBS designs. The first part of the Bell effort (references 1 and 2) consisted of an analytical study of this MBS design concept to predict its acoustic and dynamic properties, and determine its practicality.

For a traditional main rotor with equally spaced blades, the acoustic spectrum commonly contains as many as 20 or 30 harmonics, each of which is a multiple of the fundamental blade-passage frequency. The blade-passage frequency is defined as $\mathrm{nP}$, where $\mathrm{P}$ is the rotor rotational frequency ( $1 / \mathrm{rev}$ ) and $\mathrm{n}$ is the number of blades. In a typical spectral plot, these frequencies appear as pronounced, ordered "peaks" spread regularly across the acoustic spectrum. For the configuration with unevenly-spaced blades, the fundamental frequency is $\mathrm{P}$, the rotor rotational frequency itself. Since the amplitude of the harmonics of P associated with the rotating blades are directly related to the blade spacing, the use of unevenly spaced blades holds the potential for affecting sound levels and their perception.

\section{Previous Experience With Modulated Blade Spacing at Bell}

The MBS concept was proposed originally because of the success of an earlier research program at Bell having to do with an anti-torque rotor design in which a 5-blade Ducted Tail Rotor (DTR) had been flight tested at Bell, demonstrating a significant reduction in tail rotor noise (references 3 through 5). This concept had previously been used to reduce anti-torque noise in European helicopters (reference 6). The noise reduction achieved in the DTR was due not only to the duct that surrounded the tail rotor, but to significant design features incorporated in the rotor itself, one of which was modulated blade spacing. The spectrum of a baseline 5-blade evenly-spaced rotor was characterized by a series of well-defined tonal components at harmonically related frequencies with the fundamental at the blade passage frequency. Another tail rotor configuration, identical except that the blades were unevenly spaced, was subjectively much more pleasing. Its spectrum showed the acoustic energy to be distributed more uniformly throughout the audible frequency range, with a lower frequency fundamental at the rotor rotational frequency and lower amplitude harmonics in the range of the human ear's greatest sensitivity $(1,000$ to $3,000 \mathrm{~Hz})$. This uneven blade spacing provided a $5.4 \mathrm{dBA}$ reduction in the model tests, and dramatically changed the sound quality, making the tail rotor sound like a low-pitched "hum," rather than a high-pitched "buzz."

\section{Modulated Blade Spacing for Main Rotor}

The baseline 4-blade evenly-spaced rotor was based on the main rotor of the Bell Model 427 helicopter. The tip speed

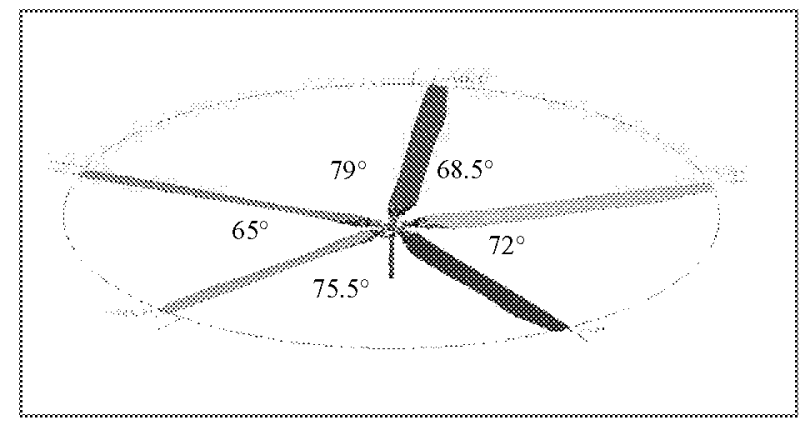

Figure 1. Modulated blade spacing

Table 1. Flight conditions used in noise predictions

\begin{tabular}{lccc}
\hline \hline & $\begin{array}{c}\text { Airspeed } \\
(\mathrm{m} / \mathrm{s})\end{array}$ & $\begin{array}{c}\text { Ascent } \\
\text { Angle } \\
(\mathrm{deg})\end{array}$ & $\begin{array}{c}\text { Nominal } \\
\text { Height at } \\
\text { overhead }(\mathrm{m})\end{array}$ \\
\hline Flyover & $58.7(114 \mathrm{kn})$ & 0.0 & 150 \\
Takeoff & $32.1(62 \mathrm{kn})$ & 18.2 & 150 \\
Approach & $30.7(60 \mathrm{kn})$ & -6.0 & 120 \\
\hline \hline
\end{tabular}

of the modified main rotor with regular spacing was reduced to decrease rotor noise, and an extra blade was added to enable performance approximating that of the 427 . The modulated rotors were derived from the 5-blade rotor design.

The noise predicted at three observer locations and three flight conditions was considered. The three locations were those required for helicopter noise certification. The three flight conditions evaluated are shown in the Table 1. For each, the velocity was assumed to be constant throughout the duration of the flight.

As compared to the baseline Model 427 rotor or the 5-blade evenly spaced rotor, the acoustical analysis found the optimum blade spacing for a 5 -blade MBS rotor for noise reduction was $72^{\circ}, 68.5^{\circ}, 79^{\circ}, 65^{\circ}$, and $75.5^{\circ}$, as shown in Fig 1. The dynamic analysis indicated that such a rotor could be designed and flown, although it would likely require some form of active transmission mount to reduce dynamic loads to the fuselage.

The noise benefits that were predicted at some flight conditions and observer locations were defined in terms of the dBA metric. Because of the inherent limitations in this and other metrics, it was felt that additional information was needed to fully assess the subjective effects of MBS. To accomplish this, a subjective evaluation, consisting of a 
Table 2. Main rotor configurations tested, with blade spacings shown for each

\begin{tabular}{|c|c|c|c|c|c|c|}
\hline $\begin{array}{c}\text { Rotor } \\
\text { Description }\end{array}$ & $\begin{array}{c}\text { 4-blade } \\
\text { Model } 427 \\
\text { Baseline }\end{array}$ & $\begin{array}{l}\text { 5-blade } \\
\text { Even } \\
\text { Spacing }\end{array}$ & $\begin{array}{l}\text { 5-blade } \\
\text { "Optimum" } \\
\text { Modulated }\end{array}$ & $\begin{array}{c}\text { 5-blade } \\
\text { Modulated } \\
\text { Candidate \#1 }\end{array}$ & $\begin{array}{c}\text { 5-blade } \\
\text { Modulated } \\
\text { Candidate \#2 }\end{array}$ & $\begin{array}{c}\text { 5-blade } \\
\text { Modulated } \\
\text { Candidate \#3 }\end{array}$ \\
\hline \multirow{4}{*}{$\begin{array}{l}\text { Angular } \\
\text { blade } \\
\text { spacing } \\
\text { (degrees) }\end{array}$} & 90 & 72 & 79 & 79.3 & 86.6 & 83 \\
\hline & 90 & 72 & 72 & 95.6 & 63.5 & 75.5 \\
\hline & 90 & 72 & 75.5 & 52.9 & 89.6 & 75.5 \\
\hline & & 72 & 65 & 79.3 & 52.1 & 63 \\
\hline $\begin{array}{c}\text { Tipspeed } \\
\mathrm{m} / \mathrm{sec}(\mathrm{ft} / \mathrm{sec})\end{array}$ & $\begin{array}{c}233 \\
(765)\end{array}$ & $\begin{array}{c}203 \\
(665)\end{array}$ & $\begin{array}{c}203 \\
(665)\end{array}$ & $\begin{array}{c}203 \\
(665)\end{array}$ & $\begin{array}{c}203 \\
(665)\end{array}$ & $\begin{array}{c}203 \\
(665)\end{array}$ \\
\hline
\end{tabular}

psychoacoustic test of MBS as applied to helicopter main rotors, was conducted and is described in this paper (and in reference 7 ).

\section{TEST DESCRIPTION}

The subjective test was conducted in June 2001 at the NASA Langley Research Center test facility in Hampton, Virginia. Bell Helicopter and sub-contractors at Penn State University were responsible for generating the rotor sound simulations, and NASA Langley personnel designed and conducted the subjective test. Results were compiled by Bell Helicopter and analyzed by NASA Langley.

\section{Rotor Designs Tested}

Three rotors from the analytical study were included in the evaluation: the baseline 4-blade Model 427 rotor, the 5 -blade evenly spaced rotor with comparable payloadrange, and the optimum 5-blade MBS rotor. In addition to these configurations, three more MBS designs were developed and included in the subjective testing, each of which had a different set of angular offsets.

These additional configurations were added to provide a broad range of modulation within the subjective study, rather than limiting it to a single MBS configuration. Table 2 lists the blade-spacing characteristics of each rotor tested. Included in the table is the shorthand designation used during data analysis and carried throughout this report.

\section{Preparation of Sound Files}

Flight Conditions and Observer Locations. Sound simulations were prepared for the flyover, takeoff, and approach conditions described previously in Table 1, using a centerline observer position. For each rotor configuration, the goal was to replicate the sound of a 427 -size helicopter passing over the observer at an altitude of 150 meters (flyover and takeoff) or 120 meters (approach). The sound was set up to begin as the hypothetical aircraft was approaching the observer position, continue through the overhead position, and end during the downrange portion of the overflight.

Analytical Noise Predictions. As a first step in the noise prediction process, rotor airloads were analytically predicted at the specific flight conditions desired. As in the analytical study, these predictions were made using Bell's airloads program known as COPTER. The airloads were then input into a modified version of the WOPWOP noise prediction program (reference 8 ) to calculate the acoustic time histories. This was done for each rotor configuration and flight condition used in the subjective testing. A total of 18 such time histories were produced (6 rotor configurations times 3 flight conditions).

The analytically-derived time histories were converted to sound files for playback on a computer-controlled audio system. An empirically-based high frequency component, based on measured M427 data, was combined with the predicted acoustic time histories to increase the realism of the test stimuli. The high-frequency components were derived by applying an $880 \mathrm{~Hz}$ high-pass filter to flight test measurements of the Bell 427 helicopter. A different highfrequency data set was created for each of the three flight conditions, using measurements from the appropriate manuver. The amplitudes of these added high-frequency components were adjusted subjectively so that a realistic sound was achieved while still allowing the main rotor characteristics to be clearly audible. The same level $(75 \%$ of the measured amplitude) was used for all sounds.

As the takeoff sounds were relatively quiet, the levels in the sound files were increased by $10 \mathrm{~dB}$ above the predicted levels to bring them to levels comparable in loudness to the other flight conditions. Overflight time histories of the final test stimuli, predicted main rotor noise together with the added high frequency component, as defined in the sound files and as played to the subjects, are presented in Figure 2 for the flyover, approach, and takeoff conditions. 

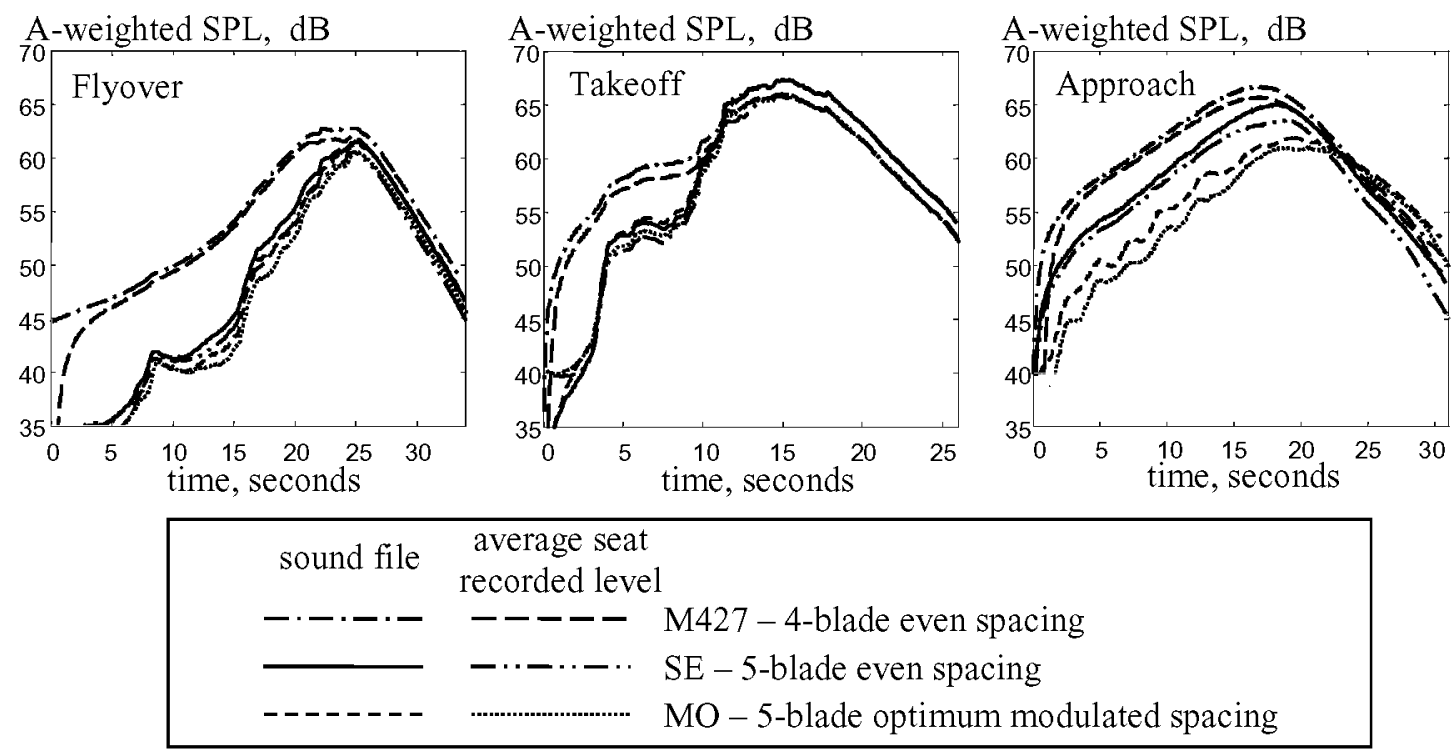

Figure 2. Sound file time histories compared to those recorded at test subjects head position

Additional information as to the analytical production of the sound stimuli is given in references 1 and 2 .

The time histories were high-pass filtered at $15 \mathrm{~Hz}$ to remove energy from the signals that the playback system could not reproduce, and preprocessed to account for the frequency response of the playback system.

The eighteen test stimuli, corresponding to the six rotor configurations and three flight conditions, are identified using their shorthand notation in Table 3 . All sounds were

Table 3. Shorthand notation for the stimuli used in subjective tests

\begin{tabular}{lccc}
\hline \hline & Flyover & Takeoff & Approach \\
\hline $\begin{array}{l}\text { 4-blade Model 427 } \\
\text { Baseline }\end{array}$ & M427fo & M427to & M427ap \\
$\begin{array}{l}\text { 5-blade Even } \\
\text { Spacing }\end{array}$ & SEfo & SEto & SEap \\
$\begin{array}{l}\text { 5-blade "Optimum" } \\
\text { Modulated }\end{array}$ & MOfo & MOto & Moap \\
$\begin{array}{l}\text { 5-blade Modulated } \\
\text { Candidate \#1 }\end{array}$ & C1fo & C1to & C1ap \\
$\begin{array}{l}\text { 5-blade Modulated } \\
\text { Candidate \#2 }\end{array}$ & C2fo & C2to & C2ap \\
$\begin{array}{l}\text { 5-blade Modulated } \\
\text { Candidate \#3 }\end{array}$ & C3to & C3fo & C3ap \\
\hline \hline
\end{tabular}

played to forty test subjects for evaluation, using a numerical category scaling design, in which the subject was asked to rate the noisiness of each overflight sound on a scale of 0 to 10 .

\section{Test Facilities}

The test was conducted in an anechoic room at NASA Langley Research Center, building 1208. The room is $11 \mathrm{ft}$ by $10 \mathrm{ft}$ by $15 \mathrm{ft}$ and lined with 16 inch foam wedges. Three loudspeakers were used: (1) a Velodyne FSR-18 subwoofer system, used to present the components of the test signals below $80 \mathrm{~Hz}$, (2) a Mackie HR824 studio monitor, used to present the components of the test signals between $37 \mathrm{~Hz}$ and $650 \mathrm{~Hz}$, and (3) another Mackie HR824 studio monitor, used to present all the components of the test signals above $37 \mathrm{~Hz}$. An Ashly XR2001 electronic crossover was used to filter the low frequency portions of the signal. Subjects were seated in two chairs in the room for the test sessions (see Figure 3 ). The signals received by

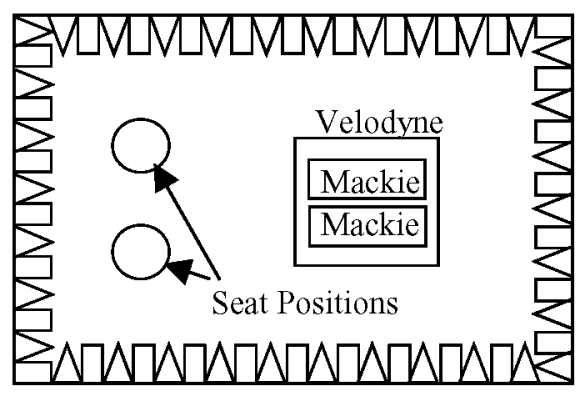

Figure 3. Relative positions of test subjects and speakers in anechoic room 
microphones placed at the equivalent subject head positions, in the absence of subjects and chairs, were measured, and a digital filter was designed to equalize the loudspeaker responses at those positions.

\section{Selection and Screening of Subjects}

Forty subjects were used in the test. The subjects were chosen from volunteers in the community, and were paid for their participation. Instructions to the recruiter were to identify and screen 40 subjects over 18 years old with at least $1 / 3$ of them male and $1 / 3$ to be female. These subjects were chosen from the general population, and were each given audiograms prior to testing. They were required to have hearing acuity within $40 \mathrm{~dB}$ of the ISO threshold. Twenty-four females aged between 23 and 68, with an average age of 41.8 years, and 16 males between 19 and 65 , with an average age of 38.1 years participated in the study. The average age of the total subject group was 40.3 years.

\section{Test Stimulus Levels}

The flyover and approach sounds were presented to the subjects at levels corresponding to those predicted to occur in reality (designated $0 \mathrm{~dB}$ ). As mentioned previously, the takeoff stimuli were played at levels $10 \mathrm{~dB}$ above those predicted so that they were of comparable loudness to the other stimuli. The purpose of this study was to compare rotor configurations within flight conditions, as comparisons across flight conditions would not be useful, so this difference in relative levels was not significant. In addition, the SEfo (5-blade, even spacing) stimulus was presented at three other levels $(-5 \mathrm{~dB},+5 \mathrm{~dB}$, and $+10 \mathrm{~dB})$. These added stimuli were intended to relate the subjective scale results to measured sound levels. The resulting 21 stimuli were each repeated for a total of 42 test sounds.

\section{Scaling Method}

The Numerical Category Scaling (NCS) method was used in this test. Subjects were asked to rate the noisiness of each sound they heard. The rating was to be marked on a continuous line, numbered 0 to 10 (see Figure 4). The descriptor "noisy" was used rather than "annoying" as annoyance may be difficult to judge in a test situation, which is unrepresentative of a real environment.

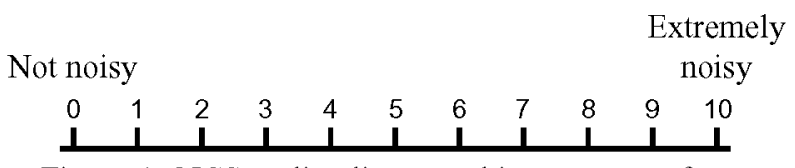

Figure 4. NCS scaling line on subject response form

\section{Test Procedure}

Subjects were tested in groups of two. Prior to testing, the subjects were given general information as to the purpose of the test and signed a consent form. They then were given specific instructions describing the NCS test method to be used. After reading the instructions the subjects heard a set of five of the stimuli used in the test to introduce them to the sounds they were about to hear. A short practice session was then completed to provide each subject a chance to become familiar with the test procedure.

The 42 test sounds were presented to the subjects in a randomized order in two sessions of 21 sounds each. The order of presentation of the two sessions was varied between groups of subjects, and the order of presentation of the sounds within each session was reversed for half the subject groups, to counteract any presentation order effects.

\section{TEST RESULTS}

Scores were entered into Microsoftß Excel 2000 spreadsheets, reordered and read into SPSS® for Windows version 10.1, which was used for all statistical calculations. Some mathematical calculations were performed using MATLAB® version 6.0 .

The positions of the subjects' marks along the 0 to 10 scaling line were measured to quantify the subjective score. Values for the scores for each sound were averaged across both presentations and all subjects. The surrounding 95\% confidence interval (C.I.) was also calculated (that is, the range with a statistically $95 \%$ confidence of containing the true value of the mean). Some subjects scored consistently low, some scored consistently high but, taken as a group, the scores were normally distributed (as indicated by the statistical calculations of skewness). Student's t-tests were applied to the mean values to determine which sounds could be considered statistically different in their subjective rating at the $95 \%$ level.

The SEfo stimulus was presented to the subjects at a total of four levels, the level equal to that predicted for the flyover case $(0 \mathrm{~dB})$, and that level $-5 \mathrm{~dB},+5 \mathrm{~dB}$ and $+10 \mathrm{~dB}$. The average scores for these four events were used to calibrate the subjective scale in terms of equivalent SEfo stimuli. A polynomial fit of the levels of the four presentations of SEfo on the scores was derived in MATLABß, and equivalent levels were calculated from the scores for the other events, using this fit as indicated in Figure 5. For example, a stimulus that received a subjective scale value of 4.2 , as shown in Figure 5, would be given a value of $2.5 \mathrm{~dB}$ relative to the SEfo at its predicted level. In this way, all noisiness scale values were converted to a $\mathrm{dB}$ scale of Equivalent Subjective Levels. These relative levels are effectively the change in level of SEfo from its predicted 
level that is required to make it subjectively equivalent to the test stimulus, and are designated $\triangle \mathrm{ESL}$. The bounds of the $95 \%$ C.I. were also converted to $\triangle \mathrm{ESL}$ in the same way. In $\mathrm{dB}$, the $95 \%$ C.I. for the 18 test stimuli ranged from 2.2 to 4.1 , with a mean of 3.0 .

Table 4 shows the subjective scores converted to $\triangle \mathrm{ESL}$ for the three flight conditions, flyover, takeoff, and approach. Comparison with the dBA values shown in Figure 2 is instructive. For the approach condition, Figure 2 shows that M427 in general has a higher dBA value than SE, which in turn is higher than MO. By contrast the results in Table 4 show that M427 has a very slightly lower $\triangle E S L$ value than $\mathrm{SE}$ with $\mathrm{MO}$ noticeably higher. For the flyover and takeoff conditions, Figure 2 shows SE and MO having equivalent $\mathrm{dBA}$ levels, with both being lower than M427. For these conditions, Table 4 shows that SE has a lower $\triangle \mathrm{ESL}$ than MO or M427.

The groupings marked in Table 4 indicate those sounds that could not be shown to be statistically different at the $95 \%$ probability level. For the approach flight condition, two overlapping groups of sounds were formed, one containing all the sounds except for the $\mathrm{C} 2$ case, and another containing all the sounds except SE and M427. Thus C2 was found subjectively noisier than the rest, and SE and M427 were found less noisy. For the flyover condition, the evenly spaced 5-bade configuration (SE) was shown to be statistically different from the other configurations (in this case, less noisy). For the takeoff condition, SE was found less noisy than MO and M427, which in turn were less noisy than the $\mathrm{C} 1, \mathrm{C} 2$ and $\mathrm{C} 3$ configurations.

For the 5-blade configurations, these results indicate that the SE configuration (even spacing) is judged to be less noisy than any of the modulated spacings; within the modulated spacings, $\mathrm{MO}$ is perhaps less noisy than $\mathrm{C} 1, \mathrm{C} 2$ and $\mathrm{C} 3$ but not strongly so. $\mathrm{C} 2$ is generally least preferred of the modulated spacings.

\section{Metric Considerations}

As the results of this test disagreed with the results of the analytical study, which were based on the A-weighted metric, an analysis was performed to find a better predictor of subjective response to these sounds. Several metrics were calculated for the test stimuli from recordings made in the subject seat positions with one inch B\&K 4145 microphones. The performance of each metric was assessed by correlating its value with the Equivalent Subjective Levels as defined by the subjective test. Results are shown in Table 5. Only data for the 18 test stimuli were included in this analysis; the 3 added SEfo stimuli used to define the fit between subjective scale and measured level were omitted. Because these 3 stimuli covered a wider range of levels, they would give a strong relationship between ESL and any metric that accounted for "loudness"

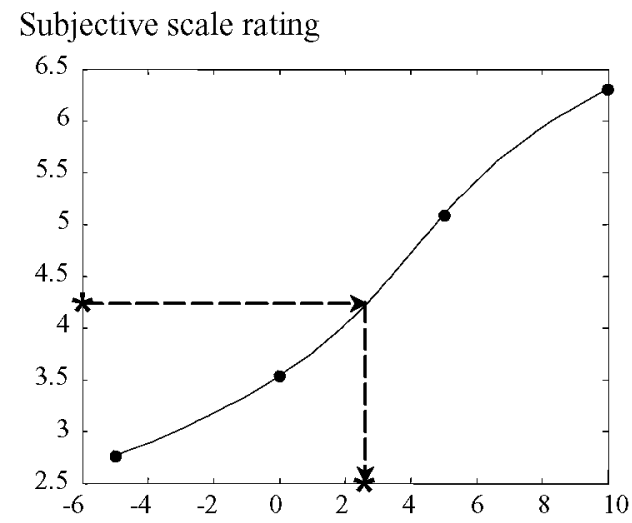

Delta Equivalent Subjective Level, $\triangle \mathrm{ESL}, \mathrm{dB}$

Figure 5. Polynomial fit through the subjective scores for the SEfo stimulus

Table 4. Subjective ratings, $\triangle \mathrm{ESL} \mathrm{dB}$, for 3 flight conditions and 6 rotor configurations. Groupings indicate values that were not found to be statistically different at a $95 \%$ probability level.

\begin{tabular}{cccc}
\hline \hline Configuration & Flyover & Takeoff & Approach \\
\hline SE & 0.00 & 1.80 & 5.42 \\
M427 & 3.84 & 3.76 & 5.38 \\
MO & 2.68 & 3.65 & 7.03 \\
C1 & 3.16 & 6.94 & 6.66 \\
C3 & 3.34 & 6.83 & 7.08 \\
C2 & 2.64 & 8.11 & 8.11 \\
\hline \hline
\end{tabular}

level. For this study it was decided to omit these 3 stimuli so that metrics accounting for other factors besides level would be emphasized.

Any of the complex non-linear loudness-type metrics such as Perceived Loudness (PL) (reference 10), Perceived Noise Level (PNL) (reference 10), and Loudness Level (LL) (reference 11) performed well. For each metric, four values were calculated: maximum value computed over 0.5 second, maximum value corrected for tonal content, maximum value corrected for duration, and maximum value corrected for both tonal content and duration. The $10-\mathrm{dB}$ down duration correction, as used in the calculation of Effective Perceived Noise Level (EPNL) in Federal Aviation Regulation-36 (FAR-36) (see reference 10), improved the correlation between subjective result and predicted metric, but the tone correction, as specified in FAR-36, degraded the metric performance. None of the simple linear weighted metrics (reference 10) performed as 
Table 5. Pearson correlation coefficients between $\triangle \mathrm{ESL}$ and metrics for the NCS test

\begin{tabular}{|c|c|c|c|c|}
\hline \multirow{3}{*}{$\begin{array}{l}\text { Metric } \\
\text { Tone correction } \\
\text { Duration correction }\end{array}$} & \multicolumn{4}{|c|}{ Correlation Coefficients } \\
\hline & \multicolumn{2}{|c|}{$\underline{\text { None }}$} & \multicolumn{2}{|c|}{$\underline{\text { FAR } 36}$} \\
\hline & $\underline{\text { None }}$ & $\underline{10-\mathrm{dB} \text { down }}$ & $\underline{\text { None }}$ & $\underline{10-\mathrm{dB} \text { down }}$ \\
\hline $\mathrm{PL}(\mathrm{dB})$ & $0.688(* *)$ & $0.769{ }^{(* *)}$ & $0.661(* *)$ & $0.699(* *)$ \\
\hline LL (phons) & $0.715\left(^{* *}\right)$ & $0.755(* *)$ & $0.568\left(^{*}\right)$ & $0.666(* *)$ \\
\hline PNL (dB) & $0.741(* *)$ & $0.739(* *)$ & $0.679(* *)$ & $0.673(* *)$ \\
\hline B-weighted (dB) & $0.566(*)$ & $\left.0.5877^{*}\right)$ & $0.471\left(^{*}\right)$ & $0.522\left(^{*}\right)$ \\
\hline A-weighted (dB) & 0.225 & $0.523\left(^{*}\right)$ & 0.139 & 0.450 \\
\hline C-weighted (dB) & 0.303 & 0.438 & 0.247 & 0.380 \\
\hline Unweighted (dB) & 0.287 & 0.430 & 0.229 & 0.370 \\
\hline
\end{tabular}

well as the non-linear metrics. The high correlation values agree with the hypothesis that subjective response is dominated by "loudness" and that other factors are of lesser importance for these stimuli.

However, the correlations in Table 5 are not perfect, so in a further attempt to improve metric performance, the Sound Quality metrics "Roughness" and "Fluctuation Strength" were calculated (references 12,13, and 14). These metrics are designed to rate sounds whose level varies over time about some mean value: Roughness for modulation frequencies between 15 and $300 \mathrm{~Hz}$; and Fluctuation strength for modulation frequencies below $15 \mathrm{~Hz}$. However, these metrics are designed to assess steady-state sounds and not sounds like the test stimuli with large level changes. Maximum and average values for both Roughness and Fluctuation Strength were calculated for the test sounds, to see if they could be useful in assessing timevarying sounds. On their own, these metrics did not correlate well with subjective response. When used in conjunction with $\mathrm{PL}$ with the 10-dB-down duration correction and no tone correction, which was the best of the metrics shown in Table 5, no improvement to predictive ability was shown.

\section{DISCUSSION AND RECOMMENDATIONS}

The subjective differences between the rotor configurations shown in this subjective test do not correspond to those seen in the earlier analytical study. As the results in the analytical study were based on $\mathrm{dBA}$, these results suggest that, for these sounds, the simple $\mathrm{dBA}$ metric is not strongly indicative of subjective response.

The evenly-spaced design was found least noisy of all the 5 -blade configurations for all flight conditions. Listening to the modulated blade sounds, a "pulsing" was audible, which was not present in the sounds from the evenly-spaced blade configurations. The fundamental frequency of an evenlyspaced configuration is higher than that of the unevenlyspace configuration by a factor equal to the number of blades. For the evenly-spaced configuration this frequency is high enough that the ear hears the sound as continuous. The lower fundamental for the modulated blade spacings results in individual pulses which are heard separately. This may account for the preference for the even-spacing configurations. The lower noise produced because of the reduced tip speed of the 5-blade configuration would account for the preference for the evenly-spaced 5-blade configuration over the 4-blade configuration seen for the flyover and takeoff flight conditions.

Little difference among the four modulated blade-spacing configurations was shown. The optimum spacing configuration was found significantly less noisy than the other three configurations only for the takeoff condition.

\section{Recommendations for Perceived Noise Reduction}

These subjective test results indicate that main rotors with modulated blade spacing do not offer significant improvements in perceived noise as had been originally hoped. Although the MBS concept has been successfully applied to a helicopter tail rotor, its application to main rotors showed no benefits, probably because of the much lower blade passage frequencies common in main rotors. A general rule of thumb may be that MBS improves rotor noise if the shaft rotation frequency is sufficiently high so that individual blade pulses are not distinguishable. Below that frequency, the perceptible sound of the individual pulses becomes objectionable, overriding the "blending" effect which benefited Bell's ducted tail rotor. 


\section{Possible Application for UAV Main Rotors}

An alternative application for the MBS main rotor is in small rotorcraft such as many Unmanned Airborne Vehicles (UAV's). The blade passage frequencies of UAV main rotors are similar to that of many traditional helicopter tail rotors, and thus the sound should be similar to that of a tail rotor. For this reason, the MBS rotor concept as applied to a UAV (tiltrotor, helicopter, or any small rotor configuration) could provide acoustic benefits similar to that experienced in Bell's Ducted Tail Rotor program discussed earlier in this paper.

At this point, UAV's are used in military, rather than in commercial applications. As these relatively new machines become more common, perceived noise may become more important. The use of the MBS rotor concept has the potential to reduce perceived noise for these vehicles.

\section{CONCLUSIONS}

1. No evidence for a subjective improvement in main rotor noise due to Modulated Blade Spacing was found.

2. There is a tendency for the evenly-spaced 5-blade configuration to be preferred over the 4-blade configuration, which illustrates the benefit of reduced tip speed for rotor noise reduction.

3. Little difference among the four modulated bladespacing configurations was shown. The optimum spacing configuration was rated significantly better than the other three configurations only for the flyover condition

4. The results of this test suggest that the $\mathrm{dBA}$ metric did not correspond well to the subjective response to the Modulated Blade Spacing configurations. Loudness Level, Perceived Loudness and Perceived Noise Level predicted subjective response well, especially when a $10-\mathrm{dB}$ duration correction was applied.

\section{ACKNOWLEDGMENTS}

Participation of BHTI and Penn State University personnel in this work was funded under contract NAS1-00091, Task 6. The authors wish to acknowledge Robert Baals, Clyde G. Medley, Jaye Moen, Carlton Pike, and Regina Johns for their help in conducting the test at NASA Langley Research Center. Also, we acknowledge the work of Rick Riley and John Schillings of Bell Helicopter Textron, Inc.

\section{REFERENCES}

1. Edwards, B. and Cox, C., "Revolutionary Concepts for Helicopter Noise Reduction - S.I.L.E.N.T. Program," Bell Helicopter Textron Incorporated Report 699-099-
529, 23 February 2001. (NASA Contractor Report - in preparation)

2. Brentner, K. S., Edwards, B.; Riley, R. G.; Schillings, J., "Predicted Noise for a Main Rotor with Modulated Blade Spacing," American Helicopter Society 58th Annual Forum, Montreal, Canada, 11-13 June 2002.

3. Edwards. B.; Andrews, J., Rahnke, C., "Ducted Tail Rotor Designs for Rotorcraft and Their Low Noise Features," Paper 18, AGARD Flight Integration Panel Symposium on Advances in Rotorcraft Technology, Ottawa, Ontario, Canada, 27-30 May 1996.

4. Riley, R. G., "Effects of Uneven Blade Spacing on Ducted Tail Rotor Acoustics," American Helicopter Society 52nd Annual Forum, Washington, D. C., 4-6 Jun 1996.

5. Andrews, J. R.; Riley, R. G. Rahnke, C., "Design and Testing of a Ducted Tail Rotor Concept Demonstrator for a Model 222U Helicopter," Paper 4, 22nd European Rotorcraft Forum and 13th European Helicopter Association Symposium, Brighton, England, 17-19 September 1996.

6. Vialle, M. and Arnaud, G., "A New Generation of Fenestron Fan-In-Fin Tail Rotor on EC-135," Nineteenth European Rotorcraft Forum, 14-16 September 1993.

7. Edwards, B., "Psychoacoustic Testing Of Modulated Blade Spacing For Main Rotors," Bell Helicopter Textron Incorporated Report 699-099-536, 23 October 2001. (NASA Contractor Report - in preparation)

8. Brentner, K. S., "Prediction of Helicopter Discrete Frequency Noise - A Computer Program Incorporating Realistic Blade Motions and Advanced Acoustic Formulation," NASA TM-87721, October 1986.

9. Finney, D.J., Probit Analysis, Cambridge University Press, 1977.

10. Pearsons, K. S. and Bennett, R. L., "Handbook of Noise Ratings," NASA CR-2376 April 1974.

11. International Standards Organization, "Method for Calculating Loudness Level (Method B)," ISO R532, 1996.

12. Staff of MTS Systems, "Sound Quality" Users Guide,” MTS Systems Corporation, Minnesota, 1998.

13. Zwicker, E. and Fastl, H., Psychoacoustics: Facts and Models, Springer-Verlag, 1990.

14. Aures, W., "Ein Berechnungsverfahren der Rauhigkeit," Acoustica 58, 268-281, 1985 